\title{
Correction to: Prognosticating Survival in Hepatocellular Carcinoma with Elevated Baseline Alpha-fetoprotein Treated with Radioembolization Using a Novel Laboratory Scoring System: Initial Development and Validation
}

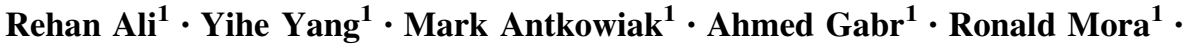 \\ Nadine Abouchaleh ${ }^{1}$ - Ali Al Asadi ${ }^{1} \cdot$ Laura Kulik $^{3} \cdot$ Daniel Ganger $^{3}$. \\ Michael Abecassis ${ }^{2} \cdot$ Nitin Katariya $^{2} \cdot$ Mary Mulcahy $^{4}$ - Al Benson ${ }^{4}$. \\ Devalingam Mahalingam $^{4}$ - Bartley Thornburg ${ }^{1}$ - Samdeep Mouli ${ }^{1}$ • \\ Robert J. Lewandowski ${ }^{1,3} \cdot$ Riad Salem $^{1,2,3} \cdot$ Ahsun Riaz ${ }^{1,5}$ \\ Published online: 6 February 2020 \\ (C) Springer Science+Business Media, LLC, part of Springer Nature and the Cardiovascular and Interventional Radiological Society of Europe \\ (CIRSE) 2020
}

Cardiovasc Intervent Radiol (2019) 42:700-711

https://doi.org/10.1007/s00270-019-02191-z

The name of the eleventh author is listed incorrectly in the published article as Nitin Kataraya. The correct name is Nitin Katariya.
Publisher's Note Springer Nature remains neutral with regard to jurisdictional claims in published maps and institutional affiliations.

The original article can be found online at https://doi.org/10.1007/ s00270-019-02191-z.

Ahsun Riaz

ahsun-riaz@northwestern.edu

1 Department of Radiology, Section of Interventional Radiology, Northwestern University, Chicago, IL, USA

2 Division of Transplant Surgery, Department of Surgery, Northwestern University, Chicago, IL, USA

3 Division of Hepatology, Department of Medicine, Northwestern University, Chicago, IL, USA

4 Division of Oncology, Department of Medicine, Northwestern University, Chicago, IL, USA

5 Feinberg School of Medicine, Northwestern University, 676 N. St. Clair, Suite 800, Chicago, IL 60611, USA 